\title{
Glutathione Metabolism of the Erythrocyte
}

\author{
THE ENZYMIC CLEAVAGE OF GLUTATHIONE-HAEMOGLOBIN PREPARATIONS \\ BY GLUTATHIONE REDUCTASE
}

\author{
By SATISH K. SRIVASTAVA AND ERNEST BEUTLER \\ Division of Medicine, City of Hope National Medical Center, Duarte, Calif. 91010, U.S.A.
}

(Received 20 April 1970)

A complex of haemoglobin and GSH was prepared by incubating haemoglobin with GSH and acetylphenylhydrazine. GSH could be released from the crude preparation by incubation with NADPH. However, when the haemoglobin preparation was separated from glutathione reductase by DEAE-Sephadex chromatography, NADPH no longer released GSH. Rather, the addition of a combination of either partially purified human erythrocyte or crystalline glutathione reductase and NADPH was required to release GSH from the haemoglobin-GSH complex. This complex is commonly believed to represent a mixed disulphide of GSH and the cysteine- $\beta$-93 thiol group. This interpretation was supported by the finding that prior alkylation of available haemoglobin thiol groups prevented the formation of the complex. By using haemoglobin- $\left[{ }^{35} \mathrm{~S}\right] \mathrm{GSH}$ complex as a substrate, it was shown that GSH itself released the radioactivity from the complex only very slowly. In contrast, the release of $\left[{ }^{35} \mathrm{~S}\right] \mathrm{GSH}$ was very rapid in the presence of NADPH and glutathione reductase. This suggests that the cleavage of the haemoglobin-GSH complex is not mediated by GSH with cyclic reduction of GSSG formed, but rather proceeds enzymically through glutathione reductase.

Allen \& Jandl (1961) and Huisman \& Dozy (1962) have shown that normal adult haemoglobin can form complexes with GSH. Their formation may be of importance both in normal erythrocyte ageing and in the pathogenesis of drug-induced haemolytic anaemia. It has been suggested by several workers (Allen \& Jandl, 1961; Huisman \& Dozy, 1962; Jacob, Brain, Dacie, Carrell \& Lehmann, 1968b; Jacob, Brain \& Dacie, 1968a) that these complexes are mixed disulphides of GSH and cysteine- $\beta-93$ of haemoglobin. The nearness of the readily accessible thiol group of cysteine-93 of the $\beta$ chain to the proximal histidine residue, to which haem is attached, and the apparent participation of disulphides in Heinz-body formation have focused attention on the role of such haemoglobin-GSH complexes in haemolytic disease (Jacob et al. $1968 a, b)$. However, the fate of complexes of GSH and haemoglobin has received only scant attention.

In the present study we have investigated the capacity of the erythrocyte to break such bonds once they have been formed. These studies indicate that although GSH itself has little capacity to break GSH-haemoglobin complexes, enzymic cleavage by glutathione reductase is accomplished with high efficiency.

\section{MATERIALS AND METHODS}

NADH, NADPH, GSH, GSSG, 5,5'-dithiobis(2nitrobenzoic acid), $N$-ethylmaleimide, yeast glutathione reductase (100 units/mg of protein) were purchased from Sigma Chemical Co., St Louis, Mo., U.S.A. $\left.{ }^{35} \mathrm{~S}\right] \mathrm{GSH}$ (11.2 mCi/mmol) was obtained from Schwartz BioResearch Inc., Orangeburg, N.Y., U.S.A. Crystalline human haemoglobin (' $100 \%$ pure') was purchased from Calbiochem, Los Angeles, Calif., U.S.A. However, it was found to be contaminated with glutathione reductase. DEAE-Sephadex A.50 (particle size 40-120 $\mu \mathrm{m}$ ) was purchased from Pharmacia Fine Chemicals, Uppsala, Sweden.

GSH and GSSG determinations. GSH was determined in a metaphosphoric acid filtrate by using the $5,5^{\prime}$ dithiobis(2-nitrobenzoic acid) method (Beutler, Duron \& Kelly, 1963). GSSG was determined enzymically in a trichloroacetic acid filtrate with NADPH and glutathione reductase after prior alkylation of GSH by $N$-ethylmaleimide (Srivastava \& Beutler, 1968).

Haemoglobin determinations. Haemoglobin was measured by using the cyanmethaemoglobin technique.

Glutathione reductase assays. Glutathione reductase activity was determined by incubation of samples of haemolysate or haemoglobin-GSH complexes, before or after fractionation on DEAE-Sephadex columns, with $1.22 \mathrm{~mm}$-GSSG and 3.0mM-NADPH for $2 \mathrm{~h}$ at $37^{\circ} \mathrm{C}$. The Bioch. 1970, 119 
increase in GSH concentration during the incubation period was determined by the $5,5^{\prime}$-dithiobis (2-nitrobenzoic acid) method (Beutler et al. 1963).

Purification of erythrocyte glutathione reductase. Glutathione reductase from normal erythrocytes was partially purified by ammonium sulphate fractionation as described by Beutler \& Yeh (1963). Further purification of the enzyme was achieved by DEAE-Sephadex chromatography and by heating the enzyme-rich fraction at $55^{\circ} \mathrm{C}$ for $10 \mathrm{~min}$. This resulted in a 1500 -fold purification (S. K. Srivastava \& E. Beutler, unpublished work).

Preparation of haemoglobin-GSH complex from human erythrocytes. Venous blood from normal donors was collected in heparinized tubes (2000 U.S.P. units of heparin $/ 10 \mathrm{ml}$ of blood) and was centrifuged at $1000 \mathrm{~g}$ for $30 \mathrm{~min}$ at $4^{\circ} \mathrm{C}$. Plasma and buffy coat were aspirated and the erythrocytes were washed twice by suspending them in 5-7 vol. of $0.15 \mathrm{M}$-potassium phosphate buffer, $\mathrm{pH} 7.4-$ $0.154 \mathrm{M}-\mathrm{NaCl}(1: 9, \mathrm{v} / \mathrm{v})$. Washed packed erythrocytes (1 ml), $1.0 \mathrm{ml}$ of phosphate buffer- $\mathrm{NaCl}, 10-30 \mu \mathrm{mol}$ of GSH neutralized to $\mathrm{pH} 7.0$ and $3.0 \mathrm{ml}$ of water were frozen and thawed once. Haemolysate $(4 \mathrm{ml})$ was transferred to tubes containing $5 \mathrm{mg}$ of acetylphenylhydrazine and incubated in a Dubnoff shaker at $37^{\circ} \mathrm{C}$ for $2 \mathrm{~h}$. The tubes were shaken at about 100 oscillations/min. In some experiments $3.0 \mu \mathrm{mo}$ of $\left[{ }^{35} \mathrm{~S}\right] \mathrm{GSH}(2.5 \mu \mathrm{Ci})$ were also added $/ \mathrm{ml}$ of erythrocytes. At the end of the incubation period the contents of the tubes were dialysed for $48 \mathrm{~h}$ against 1 litre of 10-times-diluted phosphate buffer$\mathrm{NaCl}$. The dialysis liquid was changed four times. Dialysed haemolysate was designated as MDl and the dialysed haemolysate where $\left[{ }^{35} \mathrm{~S}\right] \mathrm{GSH}$ was used as $M^{35}$ S. Samples of preparations $\mathrm{MDl}$ and $\mathrm{MD}^{35} \mathrm{~S}$ were taken for determination of GSH, GSSG, haemoglobin and glutathione reductase.

Fractionation of haemolysate and preparation $M D 1$. DEAE-Sephadex A-50 was equilibrated with $0.05 \mathrm{M}$ tris-HCl buffer, $\mathrm{pH}$ 7.9. A column $(45 \mathrm{~cm} \times 2.5 \mathrm{~cm})$ was packed to $25 \mathrm{~cm}$ and washed with $0.05 \mathrm{M}$-tris-HCl buffer, $\mathrm{pH}$ 7.9, until the $\mathrm{pH}$ of the eluate was 7.9. A portion $(16 \mathrm{ml})$ of preparation MDl dialysed overnight against 1 litre of 10-times-diluted phosphate buffer- $\mathrm{NaCl}$ without any change of dialysis liquid, or $16 \mathrm{ml}$ of $25 \%$ haemolysate dialysed against 1 litre of $0.05 \mathrm{M}$-tris-HCl buffer, $\mathrm{pH} 7.9$, was absorbed on a column at a flow rate of about $0.05 \mathrm{ml} /$ min. In some experiments $16 \mathrm{ml}$ of a $5 \%(w / v)$ solution of crystalline human haemoglobin was applied to the column. The column was washed with $400 \mathrm{ml}$ of $0.05 \mathrm{M}$ tris-HCl buffer, pH 7.9. Haemoglobin was eluted with a linear $\mathrm{pH}$ gradient from $\mathrm{pH} 7.9$ to $\mathrm{pH} 7.4$ by using $500 \mathrm{ml}$ of $0.05 \mathrm{M}$-tris-HCl buffer, $\mathrm{pH} 7.9$ and $500 \mathrm{ml}$ of the same buffer, pH 7.4. Haemoglobin was eluted after a bout $400 \mathrm{ml}$ of elution buffer had passed through the column. Fractions $(50 \mathrm{ml})$ were collected and freeze-dried. The dried powder of the haemoglobin-GSH complex was dissolved in water and dialysed for $2 \mathrm{~h}$ against two changes of 1 litre of water at $4^{\circ} \mathrm{C}$. Each fraction was assayed for acid-soluble GSH and GSSG. About six fractions in each experiment were devoid of free GSH, GSSG and glutathione reductase activity. The preparation of haemoglobin-GSH complex that was found to be free from glutathione reductase activity, acid-soluble GSH and GSSG was designated as MD2. These fractions were pooled and used for further experiments.
Fractions of haemoglobin obtained either from the haemolysate or from crystalline haemoglobin that were found to be free from glutathione reductase activity, GSH and GSSG were freeze-dried, dissolved in water and dialysed against water for $2 \mathrm{~h}$. The dialysed fractions were treated with GSH in the presence of acetylphenylhydrazine. Several haemoglobin fractions free from glutathione reductase were precipitated during the preparation. This might be attributed to oxidation of thiol groups other than those of cysteine- $\beta-93$, which will unfold the haemoglobin molecule (Jacob et al. 1968b). This mixed-disulphide preparation was dialysed for 4 days against 10-timesdiluted phosphate buffer- $\mathrm{NaCl}$ solution. Samples of the preparation were tested for acid-soluble GSH and GSSG, but none was found. This preparation was designated as MD3.

Preparation and fractionation of GSH-haemoglobin complex from rat erythrocytes. Rat erythrocytes react uniquely when subjected to $\mathrm{H}_{2} \mathrm{O}_{2}$ diffusion in that the GSH lost cannot be recovered as GSSG (Srivastava \& Beutler, 1969). Twice-washed erythrocytes (1 ml) were suspended in $3 \mathrm{ml}$ of phosphate buffer- $\mathrm{NaCl}$ solution with $0.014 \mathrm{M}$-glucose and $1.3 \mu \mathrm{M}-\mathrm{Na}_{2} \mathrm{CrO}_{4}$ and placed in the main compartment of a Warburg flask. Hydrogen peroxide $(0.2 \mathrm{ml} ; 30 \%)$ was placed in the centre well and the flask was incubated in a Dubnoff shaker at $37^{\circ} \mathrm{C}$ at 100 oscillations/min. At the end of the incubation period the contents of the main compartment were centrifuged and GSH and GSSG were determined in the supernatant and erythrocytes. Practically no GSSG was found in the erythrocytes and the recovery of total glutathione in the erythrocytes and supernatant was only about $20 \%$. Thus about $80 \%$ of the glutathione could have complexed with proteins, mainly haemoglobin.

A $25 \%$ frozen-and-thawed haemolysate of rat erythrocytes subjected to $\mathrm{H}_{2} \mathrm{O}_{2}$ diffusion was prepared and dialysed against 1 litre of water for $1 \mathrm{~h}$. Haemolysate $(16 \mathrm{ml})$ was absorbed on DEAE-Sephadex columns equilibrated at $\mathrm{pH} 7.9$ as indicated above. After the a bsorption of haemoglobin on the column, about $600 \mathrm{ml}$ of $0.05 \mathrm{M}$-tris-HCl buffer, $\mathrm{pH} 7.9$, was passed through the column. Haemoglobin fractions were eluted with $0.05 \mathrm{M}$-tris-HCl buffer, $\mathrm{pH}$ 7.5. The fractions rich in haemoglobin were freeze-dried and the resulting haemoglobin was dissolved in water and designated as MDR. No acid-soluble GSH or GSSG were detected in this solution. However, preparation MDR was very slightly contaminated with glutathione reductase activity.

Cleavage of GSH-haemoglobin preparations. Unless otherwise indicated the complexes of GSH and haemoglobin prepared from human or rat erythrocytes or purified human haemoglobin were subjected to reductive cleavage in the presence of glutathione reductase and reduced nicotinamide nucleotides. A preparation representing $0.47-1.9 \mu \mathrm{mol}$ of haemoglobin $\beta$-chain was incubated for $2 \mathrm{~h}$ at $37^{\circ} \mathrm{C}$ with $1.0-4.0 \mu \mathrm{mol}$ of NADPH, and 17 units of glutathione reductase (yeast) in a total volume of $1.4 \mathrm{ml}$ containing $30 \mu \mathrm{mol}$ of potassium phosphate buffer, $\mathrm{pH}$ 7.4. In each experiment control mixtures lacking glutathione reductase and NADPH were also studied. At the end of the incubation period proteins were precipitated with $3.0 \mathrm{ml}$ of metaphosphoric acid reagent and GSH was determined by the 5,5'-dithiobis(2-nitrobenzoic acid) method (Beutler et al. 1963). 


\section{Table 1. Cleavage of GSH from human haemoglobin-GSH complexes}

Preparations MD1, MD2 and MD3 were obtained as described in the Materials and Methods section. Each $1.4 \mathrm{ml}$ of the incubation system contained: preparation MDl (representing $1.9 \mu \mathrm{mol}$ of haemoglobin $\beta$-chains) or preparation MD2 (representing $0.47 \mu \mathrm{mol}$ of haemoglobin $\beta$-chains) or preparation MD3 (representing $0.56 \mu \mathrm{mol}$ of haemoglobin $\beta$-chains) or preparation MD3^ (Expt. 4), prepared from crystalline haemoglobin (representing $0.82 \mu \mathrm{mol}$ of haemoglobin $\beta$-chains); $0.2 \mathrm{ml}$ of $0.15 \mathrm{M}$-potassium phosphate buffer, $\mathrm{pH} 7.4$; and, where indicated, NADPH $(2 \mu \mathrm{mol})$, NADH $(2 \mu \mathrm{mol})$, yeast or human glutathione reductase (17 units). The tubes were incubated for $2 \mathrm{~h}$ at $37^{\circ} \mathrm{C}$. A 1500 -fold purified human glutathione reductase was used for splitting GSH from the mixed disulphide in Expt. 4. At the end of the incubation period proteins were precipitated with metaphosphoric acid and GSH was determined in the acid filtrate by the $5,5^{\prime}$-dithiobis $(2$ nitrobenzoic acid) method (Beutler et al. 1963). Abbreviations: ND, not determined; Hb, haemoglobin.

Additions to

haemoglobin-GSH complex

GSH released

\begin{tabular}{|c|c|c|c|c|c|c|c|c|c|c|}
\hline \multirow[b]{2}{*}{$\begin{array}{c}\text { Expt. } \\
\text { no. }\end{array}$} & \multirow[b]{2}{*}{ NADPH } & \multirow[b]{2}{*}{ NADH } & \multicolumn{2}{|c|}{$\begin{array}{l}\text { Glutathione } \\
\text { reductase }\end{array}$} & \multicolumn{2}{|c|}{ MDl } & \multicolumn{2}{|c|}{ MD2 } & \multicolumn{2}{|c|}{ MD3 } \\
\hline & & & Yeast & $\begin{array}{c}\text { Human } \\
\text { erythrocyte }\end{array}$ & $(\mu \mathrm{mol} / \mathrm{ml})$ & $\begin{array}{c}(\mu \mathrm{mol} / \mu \mathrm{mol} \\
\text { of } \mathrm{Hb} \\
\beta \text {-chain })\end{array}$ & $(\mu \mathrm{mol} / \mathrm{ml})$ & $\begin{array}{c}(\mu \mathrm{mol} / \mu \mathrm{mol} \\
\text { of } \mathrm{Hb} \\
\beta \text {-chain })\end{array}$ & $(\mu \mathrm{mol} / \mathrm{ml})$ & $\begin{array}{c}(\mu \mathrm{mol} / \mu \mathrm{mol} \\
\text { of } \mathrm{Hb} \\
\beta \text {-chain })\end{array}$ \\
\hline 1 & - & - & - & - & 0 & 0 & 0 & 0 & 0 & 0 \\
\hline 2 & + & - & - & - & 0.244 & 0.128 & 0 & 0 & 0 & 0 \\
\hline 3 & + & - & + & - & 0.247 & 0.129 & 0.066 & 0.141 & 0.058 & 0.104 \\
\hline 4 & + & - & - & + & ND & ND & ND & ND & $0.106^{\star}$ & $0.129 \star$ \\
\hline 5 & + & - & - & + & ND & ND & 0.073 & 0.155 & ND & ND \\
\hline 6 & - & - & + & + & ND & ND & 0 & 0 & ND & ND \\
\hline 7 & - & + & - & - & ND & ND & 0 & 0 & ND & ND \\
\hline 8 & - & + & + & - & ND & ND & 0.066 & 0.141 & ND & ND \\
\hline 9 & - & + & - & + & ND & ND & 0.071 & 0.151 & ND & ND \\
\hline
\end{tabular}

\section{RESULTS}

Cleavage of human GSH-haemoglobin preparations. Preliminary studies, in which $\left[{ }^{35} \mathrm{~S}\right] \mathrm{GSH}$ was used, indicated that in various experiments $0.08-$ $0.16 \mu \mathrm{mol}$ of GSH were bound $/ \mu \mathrm{mol}$ of haemoglobin $\beta$-chain. The preparation of GSH and human haemoglobin prepared by using acetylphenylhydrazine, GSH and haemolysate, i.e. MDl, contained no acid-soluble GSH and GSSG but contained a great deal of glutathione reductase activity. Large amounts of GSH were liberated from preparation MDl incubated with NADPH or NADPH + yeast glutathione reductase (Table 1). In contrast, when preparation MD2 or MD3 was incubated with NADPH alone, no GSH was liberated, but when they were incubated in the presence of both NADPH and glutathione reductase, either from yeast or from human erythrocytes, large amounts of GSH were liberated. Incubation of the mixed disulphide, prepared by using crystalline human haemoglobin, with a 1500-fold purified human glutathione reductase and NADPH liberated large amounts of GSH. In some experiments NADH was used as hydrogen donor for glutathione reductase instead of NADPH and was also found to be effective in bringing about the release of GSH. This is not surprising, since erythrocyte glutathione reductase is active with either nicotinamide nucleotide when GSSG serves as substrate.

The haemolysate prepared from human erythrocytes was preincubated for $10 \mathrm{~min}$ with $0.03 \mu \mathrm{mol}$ of $\mathrm{NADPH} / \mathrm{mg}$ of haemoglobin at $37^{\circ} \mathrm{C}$, and then for $20 \mathrm{~min}$ with $1.05 \mu \mathrm{mol}$ of $N$-ethylmaleimide $/ \mu \mathrm{mol}$ of titratable thiols. After extensive dialysis of this preparation it was treated in the manner described in the Materials and Methods section for the preparation of MDl. The preparation thus obtained was passed through a Sephadex G-50 column and the haemoglobin fractions free from $N$-ethylmaleimide, GSH and GSSG were treated in the usual manner with NADPH and glutathione reductase. No GSH was released.

Cleavage of rat GSH-haemoglobin preparations. Haemoglobin prepared by subjecting rat erythrocytes to oxidative stress in the presence of hydrogen peroxide was freed of GSH and GSSG by fractionation on DEAE-Sephadex columns. However, the preparation contained very small amounts of glutathione reductase activity. NADPH alone reduced the haemoglobin-GSH complex very slowly to liberate GSH. However, NADPH and yeast glutathione reductase reduced the haemoglobin-GSH complex much more rapidly.

Cleavage of haemoglobin- $\left[{ }^{35} \mathrm{~S}\right] G S H$ complex by added GSH. Various amounts of GSH were added 


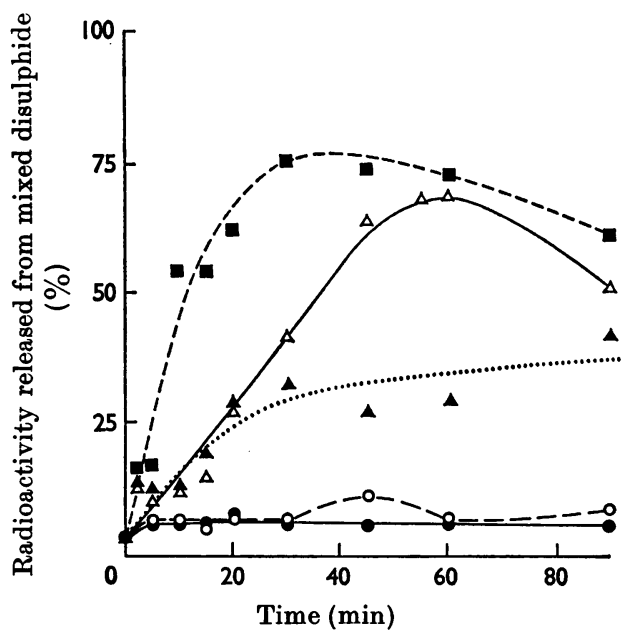

Fig. 1. Cleavage of $\left[{ }^{35} \mathrm{~S}\right] \mathrm{GSH}$-haemoglobin preparation by GSH. Preparation $\mathrm{MD}^{35} \mathrm{~S}$ was obtained by incubation of haemolysate with [ $\left.{ }^{35} \mathrm{~S}\right] \mathrm{GSH}$ in the presence of acetylphenylhydrazine and was dialysed for 4 days as described in the Materials and Methods section. It contained $0.09 \mu$ mol of glutathione $/ \mu \mathrm{mol}$ of haemoglobin $\beta$-chain. In a $1.6 \mathrm{ml}$ system preparation $\mathrm{MD}^{35} \mathrm{~S}(1.91 \mu \mathrm{mol}$ of haemoglobin $\beta$ chain) was incubated with: $\bullet$, nothing added; O, GSH $(0.064 \mu \mathrm{mol}) ; \Delta$, GSH $(0.64 \mu \mathrm{mol}) ; \Delta, \mathrm{NADPH}$ $(1.0 \mu \mathrm{mol})$; $\square$, NADPH $(10.0 \mu \mathrm{mol})$. At various timeintervals $0.1 \mathrm{ml}$ samples were withdrawn into tubes containing $0.5 \mathrm{ml}$ of $12 \%(\mathrm{w} / \mathrm{v})$ trichloroacetic acid. The tubes were centrifuged and $0.1 \mathrm{ml}$ of the clear supernatant was counted for radioactivity in a gas-flow counter. The percentage of radioactivity released from preparation $\mathrm{MD}^{35} \mathrm{~S}$ was calculated as:

Total radioactivity released from $\mathrm{MD}^{35} \mathrm{~S} \times 100$ Total radioactivity present in $\mathrm{MD}^{35} \mathrm{~S}$

to the dialysed $\mathrm{MD}^{35} \mathrm{~S}$ preparation and the mixture was incubated at $37^{\circ} \mathrm{C}$. At appropriate intervals the proteins were precipitated with trichloroacetic acid and the radioactivity of the supernatant was counted in a gas-flow counter. The addition to the medium of quantities of GSH equal to the maximum that could be released from the preparation did not release appreciable radioactivity from the haemoglobin-[ ${ }^{35}$ S $]$ GSH complex (Fig. 1). Only massive amounts of GSH released radioactivity. This is attributed to an exchange reaction between unlabelled GSH and labelled glutathione bound to the haemoglobin preparation, since total glutathione, i.e. GSH + GSSG, in the supernatant did not increase after incubation with GSH. However, the rate of release of radioactive GSH from the preparation when large amounts of GSH were added was much slower than the rate when the mixed disulphide was incubated with NADPH and glutathione reductase. Here the release of radioactivity was initially almost instantaneous. The late decline in the amount of acid-soluble radioactivity present in the incubation mixture could be attributed to the new formation of GSH-haemoglobin complexes once the supply of NADPH had been exhausted.

\section{DISCUSSION}

Erythrocytes contain large amounts of GSH. Although not all of the functions of this tripeptide are fully understood, it is believed that one role of GSH is to protect haemoglobin and other thiolgroup-containing proteins from denaturation under oxidative stress (Allen \& Jandl, 1961; Beutler, 1957). Indeed, the erythrocytes of individuals with a hereditary lack of GSH are unusually sensitive to the haemolytic effect of oxidant drugs (Prins, Oort, Loos, Zürcher \& Beckers, 1966).

When erythrocytes are exposed to oxidative stress GSH is oxidized to GSSG. This may occur through interaction of the oxidative compound with haemoglobin to form peroxides, with the subsequent oxidation of GSH through the mediation of glutathione peroxidase (Mills, 1957; Cohen \& Hochstein, 1964). Alternatively, free GS' radicals may form and may combine with one another to form GSSG (Kosower, Vanderhoff, Kosower \& Huang, 1965). It has been proposed that the formation of mixed disulphides may occur when some of these free radicals combine with the thiol group at the $\beta-93$ position of haemoglobin. Definitive proof that the binding of GSH to haemoglobin occurs at the $\beta-93$ position has not yet been obtained. However, prior treatment of haemoglobin with $N$-ethylmaleimide, which has been shown to alkylate cysteine- $\beta-93$ of haemoglobin (Riggs, 1959; Riggs \& Wells, 1960) prevents the formation of a GSH-haemoglobin complex that can be split by NADPH and glutathione reductase. Thus, it is reasonable to suppose that the complex formed does represent the disulphide of GSH and cysteine- $\beta-93$ of haemoglobin. Only with further oxidative stress is the haemoglobin molecule unfolded to expose the remaining thiol groups and to subject them to oxidation (Jacob et al. 1968b). However, it seems reasonable as a working hypothesis to consider the haemoglobin-GSH complexes we have studied to be such mixed disulphides. The fate of haemoglobin that has formed such a complex with glutathione, probably at the $\beta-93$ position, has not, to our knowledge, been studied previously. The present investigations reveal that glutathione that has become bound to human or rat haemoglobin after being exposed to the oxidative stress of incubation with acetylphenylhydrazine or hydrogen peroxide is rapidly released by incubation with NADPH or NADH. However, the reduced nicotinamide nucleotides lose their capacity to release glutathione 
from erythrocyte mixed disulphides when the glutathione reductase activity is removed from the haemolysate by column chromatography. Addition of either purified yeast glutathione reductase or the partially purified human erythrocyte enzyme restores the capacity of nicotinamide nucleotides to release GSH from haemoglobin. The possibility that the active enzyme is not glutathione reductase, but rather another enzyme contaminating the human erythrocyte glutathione reductase preparation, is rendered very unlikely by the fact that highly purified yeast glutathione reductase has the same capacity to cleave the mixed disulphide as does the less highly purified erythrocyte preparation.

The possibility has been considered that glutathione reductase actually acts on traces of GSSG that have escaped dialysis and that the GSH formed reduces a GSH-haemoglobin mixed disulphide (Hb-S-SG) and is continuously regenerated by glutathione reductase:

$$
\begin{aligned}
& \text { Hb-S-SG + GSH } \rightarrow \text { Hb-SH }+ \text { GSSG } \\
& \text { GSSG + NADPH }+\mathrm{H}^{+} \stackrel{\text { Glutathione reductase }}{2 \mathrm{GSH}+\mathrm{NADP}^{+}}
\end{aligned}
$$

Such a sequence of events has been proposed (Pihl, Eldgarn \& Bremer, 1957) for the reduction of $N N^{\prime}$-diacetylcystamine, cystamine, $N N^{\prime}$-tetramethylcystamine, $N N^{\prime}$-tetraethylcystamine, cystine and homocystine by GSH. However, this possibility is ruled out conclusively by the demonstration that the release of $\left[{ }^{35} \mathrm{~S}\right] \mathrm{GSH}$ from the mixed disulphide by GSH proceeds at an extremely slow rate, even when amounts of GSH much greater than the maximum that could be released are added. We propose that the release of GSH from the haemoglobin-GSH mixed disulphide proceeds in the single reaction catalysed by glutathione reductase:

$$
\mathrm{Hb}-\mathrm{S}-\mathrm{SG}+\mathrm{NADPH}+\mathrm{H}^{+} \underset{\mathrm{Hb}-\mathrm{SH}+\mathrm{GSH}+\mathrm{NADP}^{+}}{\stackrel{\text { Glutathione reductase }}{\longrightarrow}}
$$

Although glutathione reductase has been regarded as a relatively specific enzyme, it has been shown that in addition to GSSG it can catalyse the reduction of dihydrolipoic acid (Scott, Duncan \& Ekstrand, 1963) and possibly of the mixed disulphide of GSH and dithionitrobenzoic acid (Owens \& Belcher, 1965; Tietze, 1969). The action of glutathione reductase on mixed disulphides of haemoglobin and GSH may be of greater physiological importance. It is likely that this mechanism permits the erythrocyte to live out its normal lifespan of 120 days in the face of frequent oxidative stress, without the accumulation of large amounts of denatured haemoglobin.

Discussion held at the Glutathione Workshop at the Central Laboratory of the Netherlands Red Cross Blood Transfusion Service, Amsterdam, 1968, with Dr H. Loos and Dr G. Ellman were particularly valuable in formulating some of the concepts developed in this study. The technical assistance of Mrs Erlinda Rabano and Mrs Dena Rodittis is gratefully acknowledged. This work was made possible by a Barry T. Leithead Research Fellowship, and was supported in part by Public Health Service Grant no. HE 07449 from the National Heart Institute, and Grant no. HD 01974 from the National Institute of Child Health and Human Development.

\section{REFERENCES}

Allen, D. W. \& Jandl, J. H. (1961). J. clin. Invest. 40, 454. Beutler, E. (1957). J. Lab. clin. Med. 49, 84.

Beutler, E., Duron, O. \& Kelly, B. M. (1963). J. Lab. clin. Med. 61, 882.

Beutler, E. \& Yeh, M. K. Y. (1963). Blood, 21, 573.

Cohen, G. \& Hochstein, P. (1964). Biochemistry, Easton, 3, 895.

Huisman, T. H. J. \& Dozy, A. M. (1962). J. Lab. clin. Med. 60, 302.

Jacob, H. S., Brain, M. C. \& Dacie, J. V. (1968a). J. clin. Invest. 47, 2664.

Jacob, H. S., Brain, M. C., Dacie, J. V., Carrell, R. W. \& Lehmann, H. (1968b). Nature, Lond., 218, 1214.

Kosower, N. S., Vanderhoff, G. A., Kosower, E. M. \& Huang, P. C. (1965). Biochem. biophys. Res. Commun. $20,469$.

Mills, G. C. (1957). J. biol. Chem. 229, 189.

Owens, C. W. I. \& Belcher, R. V. (1965). Biochem. J. 94, 705.

Pihl, A., Eldgarn, L. \& Bremer, J. (1957). J. biol. Chem. 227, 339.

Prins, H. K., Oort, M., Loos, J. A., Zürcher, C. \& Beckers, T. (1966). Blood, 27, 145.

Riggs, A. (1959). Nature, Lond., 183, 1037.

Riggs, A. \& Wells, M. (1960). Fedn Proc. Fedn Am. Socs exp. Biol. 19, 78.

Scott, E. M., Duncan, I. W. \& Ekstrand, V. (1963). J. biol. Chem. 238, 3928.

Srivastava, S. K. \& Beutler, E. (1968). Analyt. Biochem. 25, 70.

Srivastava, S. K. \& Beutler, E. (1969). Biochem. J. 114, 833.

Tietze, F. (1969). Analyt. Biochem. 27, 502. 